Int. J. Curr. Res. Med. Sci. (2017). 3(9): 58-60

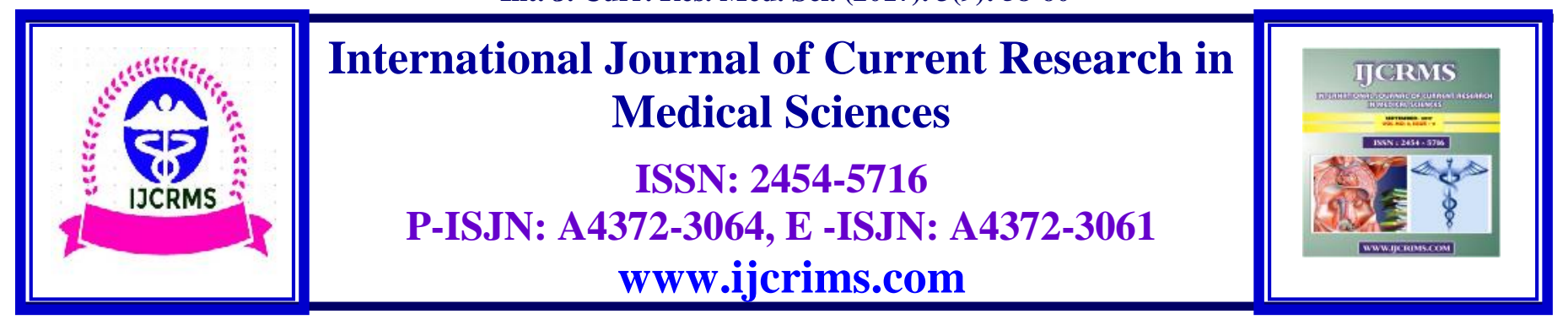

Case Report

Volume 3, Issue 9 -2017

DOI: http://dx.doi.org/10.22192/ijcrms.2017.03.09.004

\title{
Bilaterally impacted maxillary canines and premolars - A rare case report
}

\author{
* Sanjeev Soni, **Maninderdeep Kaur,*** Riponjot Singh, ****Sukhpal Kaur \\ *Professor, $* *$ Lecturer, $* * * *$ Reader, Dept. of Orthodontics and Dentofacial Orthopaedics, \\ Desh Bhagat Dental College and Hospital, Mandi gobindgarh, Punjab, 147301. \\ *** Dental hygiene student, Georgian College of Applied Arts and Technology, Barrie, Canada. \\ Corresponding Author: Sukhpal kaur, \\ Reader, Dept. of Orthodontics and Dentofacial Orthopaedics, Desh Bhagat Dental College and Hospital, \\ Mandi Gobindgarh, Punjab, 147301. \\ E-mail:docs284@gmail.com
}

\begin{abstract}
Impacted teeth and orthodontists share a long-standing relationship. Third molar and canine impactions, their effects and management have been discussed in depth in history. Impacted premolars are less commonly encountered in the literature, especially maxillary premolars. This paper describes a case report of bilaterally impacted maxillary $2 \mathrm{nd}$ premolars and canine.
\end{abstract}

Keywords: Impaction, convex profile, ectopic eruption.

\section{Case Report}

A 15 years old girl reported in the department of orthodontics and dentofacial orthopaedics with complaint of irregularly placed upper front teeth.

On intra-oral examination it was found that permanent maxillary canines and $2^{\text {nd }}$ premolars were absent bilaterally while primary maxillary canines and primary $2^{\text {nd }}$ molar were present bilaterally in maxillary arch, which were firm .Molar relationship on both sides was class $\mathrm{I}$. Maxillary central incisors were mesially rotated.
No swelling could be seen or palpated, either in the palatal vault behind the Incisors or deep in the labial sulcus for missing teeth. Facial profile of the patient was convex.

From radiographic examination, it was found that missing canines and premolars were impacted with complete root formation.(fig.1) 


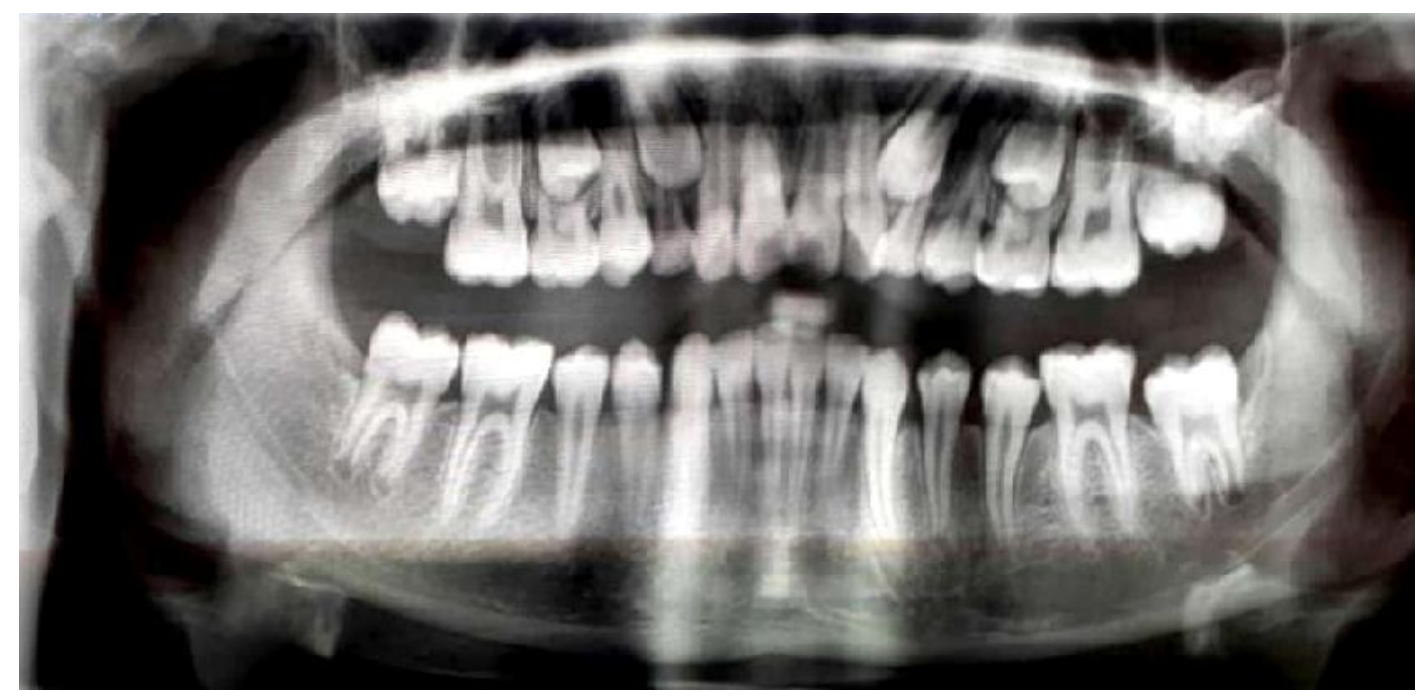

\section{Discussion}

A tooth is considered to be impacted if its eruption is prevented or blocked at its position by adjacent teeth or bone. Failure to detect and analyze the problem may lead to unnecessary space loss, crowding, collapse of the dental arch. Impaction of maxillary canine is common but impacted premolars are less common. the prevalence of impacted premolars has been found to vary according to age impacted mandibular $2^{\text {nd }}$ premolars is on $3^{\text {rd }}$ rank following the permanent molars and maxillary permanent canines ,in frequency of occurrence ${ }^{1}$ The incidence of canine impaction in the maxilla is more than twice that in the mandible. Of all patients who have impacted maxillary canines, $8 \%$ have bilateral impactions. ${ }^{2}$

Impacted canine clinically may be detected from the absence of a normal labial canine bulge, presence of palatal bulge. According to Ericson and Kurol, ${ }^{3}$ the absence of the "canine bulge" at earlier ages should not be considered as indicative of canine impaction. In their evaluation of 505 school children between 10 and 12 years of age, they found that $29 \%$ of the children had non palpable canines at 10 years, but only $5 \%$ had it at 11 years, whereas at later ages only $3 \%$ had non palpable canines. Therefore, for an accurate diagnosis, the clinical examination should be supplemented with a radiographic evaluation. Same is applicable to maxillary premolars. Panoramic radiographic examination is essential along with occlusal radiograph because
Fig. 1

sometimes palatally impacted premolars are very high in vault, near to the nasal sinus floor due to this reason they might not be detected on periapical radiograph ${ }^{4}$

Reason for impaction of tooth can be mechanical blockage, ecotopic positioning, arch length deficiency, malformed teeth, ankylosis of the tooth, trauma, retained or ankylosed primary teeth and systemic diseases. Most of the time, palatal displacement of the maxillary canine results in impaction. ${ }^{5,6}$

Treatment of impacted teeth includes observation, Intervention, relocation, and extraction. Selection of the appropriate Treatment option depends on the underlying etiological Factors, space requirements, need for extractions of primary teeth degree of impaction, and root formation of the Impacted teeth. ${ }^{7,8}$

The treatment of these clinical entities usually involves surgical exposure of the impacted tooth, followed by orthodontic traction to guide and align it into the dental arch. . But the simplest interceptive procedure that can be used to prevent impaction of permanent teeth is the timely extraction of the primary tooth hindering the eruption of permanent tooth. These impacted premolars and canines, if left unattended dentigerous cysts may develop around them ${ }^{9,10}$. So early diagnosis and appropriate treatment of impacted teeth should be done. 


\section{Financial Support and Sponsorship: Nil}

Conflicts of Interests: There are no conflicts of interests

\section{References}

1. Andreasen JO, Petersen JK, Laskin DM. "The impacted premolar," Textbook and color Atlas of Tooth Impactions: Diagnosis Treatment and prevention, Munksgaard, ICopenhagen, Denmark, 1997: 177-195.

2. Bishara SE. Impacted maxillary canines: A review. Am J Orthod Dentofacial Orthop. 1992; 101:159-71.

3. Ericson S, Kurol J. Longitudinal study and analysis of clinical supervision of maxillary canine eruption. Community Dent Oral Epidemiol. 1986;14:112-6.

4. Oikarinen VJ, Julku M. Impacted premolarsAnalysis of 10,000 orthopantomograms," Proceedings of The Finnish Dental Society, 1974 vol. 70, no. 3:95-98.

5. Power SM, Short MB. An investigation into the response of palatally displaced canines to the removal of deciduous canines and an assessment of factors contributing to a favourable eruption. $\mathrm{Br}$ J Orthod. 1993; 20: $215-23$.

6. litsas G. A review of early displaced maxillary canines: Etiology, diagnosis and interceptive treatment. Open Dent J. 2011;5:39-47.

7. Yawaka Y, Kaga M, Osanai M, Fukui A, and Oguchi H. Delayed eruption of premolars with periodontitis Of primary predecessors and a cystic lesion: a case report. International Journal of Paediatric Dentistry.2002; vol. 12(1):53-60.

8. Frank CA. Treatment options for impacted teeth. Journal of the American Dental Association 2000; vol. 131(5):623-632.

9. Hyomoto M, Kawakami M, Inoue M, Kirita T. Clinical conditions for eruption of maxillary canines and Premolars associated with dentigerous cysts. Am J Orthod Dentofacial Orthop. 2003 Nov;124(5):515-20.

10. Takagi S, Koyama S. Guided Eruption of an Impacted second premolar Associated with a Dentigerous Cyst in the Maxillary Sinus of a 6-Year-old Child:J Oral Maxillofac Surg. $1998 ; 56: 237-239$

\begin{tabular}{|c|l|}
\hline \multicolumn{2}{|c|}{ Access this Article in Online } \\
\hline Quick Response Code & Website: \\
\cline { 2 - 3 } & www.ijcrims.com \\
\cline { 1 - 2 } & Subject: \\
\hline
\end{tabular}

How to cite this article:

Sanjeev Soni, Maninderdeep Kaur, Riponjot Singh, Sukhpal Kaur. (2017). Bilaterally impacted maxillary canines and premolars - A rare case report. Int. J. Curr. Res. Med. Sci. 3(9): 58-60.

DOI: http://dx.doi.org/10.22192/ijcrms.2017.03.09.004 